\title{
Statistical characteristics of soil water content at farmland of the Horqin Sand Land
}

\author{
Shuxia Yao ${ }^{1, a^{*}}$, Chuancheng Zhao ${ }^{2, b}$, LijuanYe ${ }^{3, c}$, Xinmei Zhao ${ }^{4, d}$ and Tonghui \\ Zhang, \\ ${ }^{1}$ Lanzhou City University, Lanzhou 730070, China \\ ${ }^{2}$ Lanzhou City University, Lanzhou 730070, China \\ ${ }^{3}$ Qinghai Nationalities for University, Xining 810007, China \\ ${ }^{4}$ Department of Basic Courses, Lanzhou Institute of Technology, Lanzhou 730050, China \\ ${ }^{5}$ Cold and Arid Regions of Environmental and Engineering Research Institute, Chinese Academy of \\ Sciences, Lanzhou 730000,China \\ ayaoshuxia@163.com, b'zhao_chch1978@163.com, cyelj@Izu.edu.cn, ${ }^{\mathrm{d}}$ zhaoxm@163.com, \\ ezhangth@lzb.ac.cn
}

\begin{abstract}
Keywords: Soil water content; Farmland; Statistical analysis; Korqin Sand Land.
Abstract. Based on the observed data of soil water content (SWC) at farmland from May to September in 2009 2012, the statistical characteristics of SWC in farmland at different soil depths (from 0 to $150 \mathrm{~cm}$ ) and different months in the growing season (from May to September) in Korqin Sand Land were analyzed. In addition, by Skewness, Kurtosis test method, the normality of SWC of farmland in different soil layers and different months were tested. And then, we obtained the estimates and the confidence interval of the mean and variance for the normal distribution of SWC. The results indicated that: (1) The SWC of farmland at the same month and same soil depth passed the hypothesis testing of normal distribution at the significance level of $\alpha=0.1$; (2) SWC of farmland changed from $12 \%$ to $28 \%$ in 2009 2012; The standard deviation of SWC at farmland was 2 6; and the variation coefficients between $0 \sim 1$, that was, belonged to the medium variation; (3) SWC at farmland was highest in July, and significant difference with other month in the growing season; And hence, the estimates and confidence interval for the mean and variance of SWC in July were significantly different from other month of the growing season; (4) SWC of farmland was lowest at $0 \sim 10 \mathrm{~cm}$ and differently from other soil layer, and it was highest at $120 \sim 150 \mathrm{~cm}$; the change characteristics of the average value of SWC at farmland with soil depth was firstly increased, and then decreased, and finally increased.
\end{abstract}

\section{Introduction}

Soil water content (SWC) is the natural state variable of the land surface (Mohanty and Skaggs, 2006), and it controls several processes at or near the land surface (Teuling et al., 2006). Therefore, the study of SWC is one of the hot topics of research in the current international academic circle. For arid and semi-arid sandy land, soil water content is a key factor determining the structure and function of ecosystem in the region (Liu, 2008). And hence, the SWC is an important parameter for the study of drought characteristics in arid and semi-arid sandy land (Wang et al., 2012).

Horqin Sand Land is one of China's four major sandy lands. The ecological environment here is fragile, and SWC is a key factor for its ecosystem stability, structure and normal functioning (Yao et al., 2013). Therefore, it is necessary to analyze the statistical characteristics of SWC in the farmland which covering a large area in this region.

\section{Material and methods}

The study area is located in the southern part of the the Horqin Sand Land in eastern Inner Mongolia, China $\left(42^{\circ} 55^{\prime} \mathrm{N}, 120^{\circ} 42^{\prime}\right.$ E, $345 \mathrm{~m}$ a.s.1.). The Horqin Sand Land is one of four well-known sandy 
areas in northern China, which are generally thought to originate from sand and dust storms that occur frequently in the arid and semi-arid regions of northern China (Wang 2000).

We chose a farmland as the site to be studied, and the basic situation of the site was listed in Table 1.

Table1. Basic situations of the farmland

\begin{tabular}{cccccc}
\hline Site & Main crop & Longitude & Latitude & Altitude (m) & $\begin{array}{c}\text { Features of interference } \\
(\%)\end{array}$ \\
\hline Farmland & Corn & 120.700 & 42.930 & 359 & $<30$ \\
\hline
\end{tabular}

CNC100 (Beijing) neutron moisture meter was employed for determination of SWC. Three neutron moisture meters at the depth of $2 \mathrm{~m}$ were buried at an equal interval on each sample land for regular observation of SWC at the depth of $0 \sim 150 \mathrm{~cm}$ in farmland. Every $10 \mathrm{~cm}$ constituted a new soil layer. From early May to the end of September every year, soil was determined once every 10 day without rain, and one more time after each rainfall for 4 consecutive years (2009-2012).

Data analysis processing was completed by using 2003 software. Normality test and parameter estimation of SWC as well as analysis on the differences of SWC in different months and different soil layers were all completed using SPSS 17.0 statistical analysis software (Liu et al., 2011).

\section{Results}

"Skewness and kurtosis test method" was used for testing of $0 \sim 150 \mathrm{~cm} \mathrm{SWC} \mathrm{in} \mathrm{farmland} \mathrm{of} \mathrm{Horqin}$ Sand Land between May and September during 2009-2012. The results showed that SWC of farmland at the same soil layer in the same month passed the normal distribution test with significance level of $\alpha=0.1$, while the SWC at the same soil layer in different months didn't pass the normality test. Because the SWC at the same month changed little with soil depth, while the SWC at the same soil depth changed largely with the month;

Let $\bar{X}$ and $S^{2}$ was the unbiased estimated value of sample mean value and sample variance of SWC, respectively. The confidence interval of $\bar{X}$ and $S^{2}$ at the confidence levels of 0.95 obtained from SWC which have passed normality test in farmland was shown in Table 2. As shown in Table 2, the range of unbiased estimated of $\mu$ in farmland was $12 \% \sim 28 \%$, mainly concentrated within $15 \% \sim 25 \%$; And the confidence interval of $\mu$ was between $11 \%$ and $28 \%$.

Due to the heaviest precipitation in July in the study area (Yao et al., 2014), and given the fact that the main source of SWC in the region is recharge from precipitation (Li et al., 2010), the SWC in July is significantly higher than that in other months. As a result, both the sample mean value and the sample variance estimated value in July were greater than those in other months, and the confidence interval significantly shifted to the right compared with other months.

In addition, the the range of unbiased estimated of $\sigma^{2}$ in farmland was $6 \sim 38$, and the confidence interval of $\sigma^{2}$ was between 4 and 66. It could be seen from the statistical characteristics of SWC in farmland (Table 2), the standard deviation of SWC in farmland at different depths in different months mainly ranged from 2 to 6; the coefficients of variation of SWC in farmland of different depths in different months were all $0 \sim 1$, suggesting that both temporal and spatial variability of SWC in farmland was moderate variability. 
Table 2. Unbiased estimated and confidence interval at 0.95 levels of $\mu$ and $\sigma^{2}$ of SWC at farmland

\begin{tabular}{|c|c|c|c|c|c|c|c|c|c|}
\hline \multirow{2}{*}{$\begin{array}{c}\text { Soil } \\
\text { layers/ } \\
(\mathrm{cm})\end{array}$} & \multirow[t]{2}{*}{ Month } & \multirow{2}{*}{$\begin{array}{l}\text { Unbiased } \\
\text { estimated } \\
\text { of } \mu \\
\bar{X}\end{array}$} & \multirow{2}{*}{$\begin{array}{l}\text { Unbiased } \\
\text { estimated } \\
\text { of } \sigma^{2} \\
S^{2}\end{array}$} & \multirow[t]{2}{*}{$\begin{array}{l}\text { Confidence } \\
\text { interval of } \mu\end{array}$} & \multirow{2}{*}{$\begin{array}{c}\text { Confidence } \\
\text { interval of } \sigma^{2}\end{array}$} & \multicolumn{4}{|c|}{$\begin{array}{c}\text { Statistical } \\
\text { characteristics of SWC }\end{array}$} \\
\hline & & & & & & Min. & $x$. & $\mathrm{SD}$ & $\mathrm{CV}$ \\
\hline \multirow{6}{*}{$0 \sim 10$} & May & $12.46^{\mathrm{b}}$ & 13.71 & $(11.31,13.61)$ & $(9.28,22.29)$ & 7.59 & 21.33 & 3.62 & 0.29 \\
\hline & June & $12.86^{\mathrm{b}}$ & 11.47 & $(11.85,13.88)$ & $(7.86,18.30)$ & 8.00 & 18.67 & 3.35 & 0.26 \\
\hline & July & $15.67^{\mathrm{a}}$ & 15.90 & $(14.66,16.67)$ & $(11.50,23.92)$ & 10.46 & 21.61 & 3.95 & 0.25 \\
\hline & Aug. & $13.16^{\mathrm{ab}}$ & 9.23 & $(12.35,13.97)$ & $(6.57,14.25)$ & 10.18 & 31.00 & 3.00 & 0.23 \\
\hline & Sept. & $13.26^{\mathrm{ab}}$ & 26.75 & $(11.43,15.10)$ & $(17.30,46.80)$ & 5.41 & 22.00 & 5.09 & 0.3 \\
\hline & Mean & $13.48^{\mathrm{E}}$ & 15.41 & $(12.32,14.65)$ & $(10.50,25.11)$ & 8.33 & 22.92 & 3.80 & $0.2 \varepsilon$ \\
\hline \multirow{6}{*}{$10 \sim 30$} & May & $18.17^{\mathrm{b}}$ & 22.00 & & $(14.90,35.77)$ & 11.18 & 24.83 & 3.97 & 0.2 \\
\hline & June & $17.87^{b}$ & 13.29 & $3.96)$ & $(9.11,21.21)$ & 12.91 & 21.00 & 3.61 & 0.20 \\
\hline & July & $20.34^{\mathrm{a}}$ & 17.10 & $(19.29,21.38)$ & $(12.40,25.72)$ & 14.41 & 25.12 & 4.10 & 0.2 \\
\hline & Aug. & $17.29^{b}$ & 11.38 & $(16.39,18.19)$ & $(8.10,17.57)$ & 13.29 & 23.00 & 3.34 & 0.15 \\
\hline & Sept. & $17.78^{b}$ & 38.07 & $.97)$ & $(24.60,66.61)$ & 10.21 & 25 & 6.08 & 0.3 \\
\hline & Mean & $18.29^{\mathrm{CD}}$ & 20 . & & (13. & 12.40 & 23 & 4.22 & 0.2 \\
\hline \multirow{7}{*}{$30 \sim 60$} & May & $19.45^{\mathrm{ab}}$ & 34.67 & & $(23$ & 10.76 & & 3.47 & 0.3 \\
\hline & June & $19.71^{\mathrm{ab}}$ & 12.05 & $0.75)$ & $(8.2$ & 15.59 & 23.22 & 3.43 & 0.17 \\
\hline & July & $21.74^{\mathrm{a}}$ & & & & 18.30 & & 3.58 & 0.1 \\
\hline & Aug. & $18.99^{b}$ & 10.04 & $(18.14,19.83)$ & $(7.15,15.50)$ & 17.41 & 27.33 & 3.14 & 0.17 \\
\hline & Sept. & $18.51^{\mathrm{b}}$ & & $(17.13,19.89)$ & $(9.76,26.39)$ & 14.87 & & 3.82 & 0.2 \\
\hline & Mean & $19.68^{\mathrm{B}}$ & & .88) & $(11.62,27.43)$ & 15.39 & 26 & 3.49 & 0.2 \\
\hline & May & $17.47^{\mathrm{b}}$ & 30 & $19.18)$ & $(20.50,49.22)$ & 9.02 & 26.33 & 4.44 & 0.3 \\
\hline \multirow{5}{*}{$60 \sim 90$} & June & $18.32^{b}$ & 10 & & $(7.4$ & 14.61 & 21 & 3.26 & 0.1 \\
\hline & July & $20.44^{\mathrm{a}}$ & 13.05 & ,21.35) & $(9.43,19.63)$ & 16.34 & 25.22 & 3.58 & 0.1 \\
\hline & Aug. & $17.27^{b}$ & 6.28 & $(16.60,17.94)$ & $(4.47,9.69)$ & 16.36 & 24.33 & 2.48 & 0.1 \\
\hline & $\mathrm{S}$ & $17.06^{\mathrm{b}}$ & & & & 13.35 & & 2.85 & 0.1 \\
\hline & Mean & $18.11^{\mathrm{C}}$ & 13.77 & , 19.17) & $(9.45,22.11)$ & 13.93 & 23.98 & 3.32 & 0.20 \\
\hline \multirow{6}{*}{$90 \sim 120$} & May & $16.36^{\mathrm{b}}$ & 16.80 & (15. & $(11.40,27.32)$ & 8.58 & 23.22 & 4.05 & 0.2 \\
\hline & June & $16.91^{b}$ & 8.81 & , 17.80) & $(6.04,14.06)$ & 13.55 & 19.11 & 2.93 & 0.17 \\
\hline & July & $19.44^{\mathrm{a}}$ & 16.09 & ,20.45) & $(11.60,24.20)$ & 15.29 & 23.69 & 3.98 & 0.2 \\
\hline & Aug. & $16.61^{b}$ & 9.14 & $(15.80,17.42)$ & $(6.50,14.11)$ & 14.11 & 22.00 & 3.00 & 0.1 \\
\hline & Sept. & $17.78^{\mathrm{b}}$ & 31.53 & $(15.79,19.77)$ & $(20.40,55.15)$ & 12.20 & 22.11 & 5.53 & 0.3 \\
\hline & Mean & $17.42^{\mathrm{D}}$ & 16.47 & $(16.22,18.62)$ & $(11.19,26.97)$ & 12.75 & 22.03 & 3.90 & 0.2 \\
\hline \multirow{6}{*}{$120 \sim 150$} & May & $23.04^{b}$ & 27.79 & $(21.39,24.68)$ & $(18.80,45.18)$ & 14.40 & 29.44 & 5.21 & 0.2 \\
\hline & June & $24.41^{b}$ & 15.14 & $(23.24,25.58)$ & $(10.40,24.16)$ & 19.40 & 26.33 & 3.85 & 0.16 \\
\hline & July & $27.10^{\mathrm{a}}$ & 20.19 & $(25.96,28.23)$ & $(14.60,30.38)$ & 18.36 & 32.89 & 4.46 & 0.1 \\
\hline & Aug. & $23.99^{b}$ & 9.62 & $(23.17,24.82)$ & $(6.85,14.85)$ & 17.90 & 30.00 & 3.07 & 0.13 \\
\hline & Sept. & $25.06^{\mathrm{ab}}$ & 24.50 & $(23.31,26.82)$ & $(15.80,42.87)$ & 16.89 & 31.44 & 4.87 & 0.15 \\
\hline & Mean & $24.72^{\mathrm{A}}$ & 19.45 & $(23.41,26.03)$ & $(13.29,31.49)$ & 17.39 & 30.02 & 4.29 & 0.1 \\
\hline
\end{tabular}

Note: Different letters for average values indicate significant differences at $\mathrm{P}<0.05$.

As indicated in Figure 1, the SWC of different soil depths was all highest in July, lowest in May. And SWC of different months was all highest in $120 \sim 150 \mathrm{~cm}$, next was $30 \sim 60 \mathrm{~cm}$, and lowest in $0 \sim 10$ $\mathrm{cm}$ (Figure 1). 


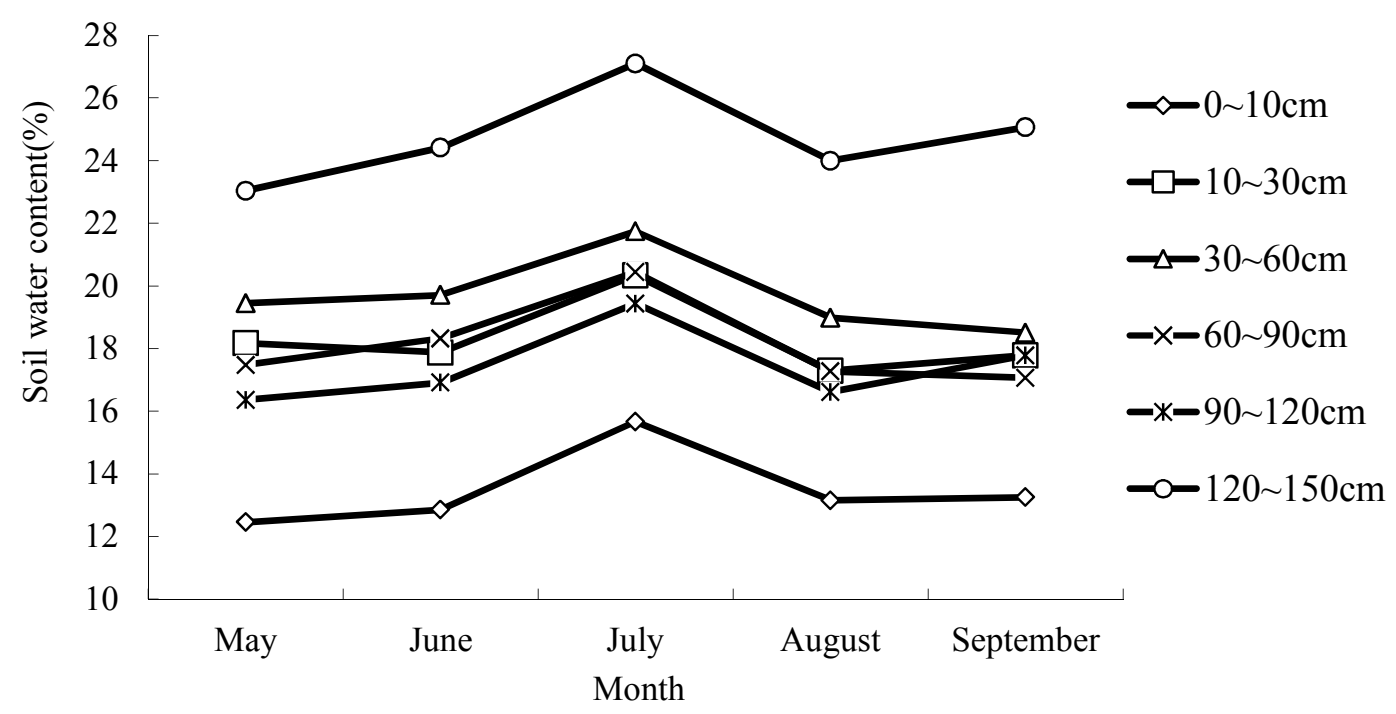

Figure 1. Variation of SWC in farmland at different soil depths along with month

\section{Conclusions}

(1) The average values of SWC in farmland of Horqin Sandy Land was $12 \% \sim 28 \%$; SWC in the same month obey normal distribution;

(2) Both the sample mean value and the sample variance estimated value of SWC in July is significantly higher than those in other months, and the confidence interval shows a trend of significantly rightward shifting;

(3) SWC of different months was all highest in $120 \sim 150 \mathrm{~cm}$, next was $30 \sim 60 \mathrm{~cm}$, and lowest in $0 \sim 10 \mathrm{~cm}$.

\section{Acknowledgments}

This study was supported by the National Natural Science Foundation of China (No. 31300388; No. 41361013); Dr. Start-up Science Research Foundation of Lanzhou City University (No. LZCUBS2013-09; No. LZCU-BS2013-12) and Chancellor Research and Innovation Fund of Lanzhou City University (No. LZCU-XZ2014-12). The authors also would like to acknowledge the helpful comments and suggestions from anonymous referees.

\section{References}

[1] B. P. Mohanty and T. H. Skaggs, Spatio-temporal evolution and time-stable characteristics of soil moisture within remote sensing footprints with varying soil, slope, and vegetation, Advances in water resources. 24 (2001) 1051-1067.

[2] A. J. Teuling, R. Uijlenhoet, F. Hupet, et al., Estimating spatial mean root-zone soil moisture from point-scale observations, Hydrol, Earth Syst. Sci. Discuss. 3 (2006) 1447-1485.

[3] X. P. Liu, Water dynamics and water reasources evaluation in Horqin Sandy Land. Cold and Arid Regions Environmental and Engineering Research Institute, Chinese Academy of Sciences. (2008).

[4] M. C. Wang, S. T. Yang, G.T. Dong, et al., Estimating soil water in Northern China based on vegetation temperature index (VTCI), Arid land geography. 35(3) (2012) 446-455.

[5] S. X. Yao, T.H. Zhang, C.C. Zhao, A comparison of soil saturated hydraulic conductivity (KFS) in different Horqin Sand Land, Acta pedologica Sinica. 50(3) (2013) 45-53.

[6] T. Wang, Land use and sandy desertification in the North China, Journal of Desert Research. 20 (2) (2000) 103-107. 
[7] Z. Liu, G. Wu, W.D. Ding, et al., SPSS statistical analysis and application, Electronic Industry Press. (2011).

[8] S.X. Yao, C.C. Zhao, T.H. Zhang, Multiple-time-scale analysis on precipitation in Naiman Banner of Horqin Sandy Land in 1970-2010, Journal of Desert Research. 34(2) (2014) 542-549.

[9] Y.Q. Li, T.H. Zhang, X.P. Liu, et al., Change Pattern of Soil Water Content in Different Dunes and Grassland in Horqin Sandy Land, Bulletin of Soil and Water Conservation. 30(3) (2010) 31-35. 